\title{
Lessons Learned from Implementing Project Management Games
}

\author{
David Rumeser ${ }^{1}$, Margaret Emsley ${ }^{2}$, \\ ${ }^{I}$ PT. Pelabuhan Indonesia II (Persero), david.rumeser@indonesiaport.co.id \\ ${ }^{2}$ The University of Manchester, margaret.emsley@manchester.ac.uk
}

\section{Abstract}

The purpose of this paper is to identify the principles governing successful project management serious (educational) game design and implementation by identifying lessons learned from implementing such games. This paper applied a triangulation method that qualitatively blends the perspectives of project management practitioners, game designers, and learners. The findings of this paper suggest principles of game realism, context, display, gameplay clarity, target audience, feedback, setting, debriefing, communication mode, and personalization. The main potential beneficiaries of this research include project management educators, trainers, students, training participants, and game designers. The study provides a comprehensive project management game design and implementation guideline that could help improve the quality of project management serious games. This paper is the first exploratory study to blend the perspectives of learners (students), serious game experts, and experienced project management practitioners in order to identify the key principles of delivering successful project management educational or serious games.

Keywords: Project Management, Serious Games, Training, Education, Design and Implementation

\section{Introduction}

One of the main challenges in project management (PM) education is a divide between what learners learn at training institutions and universities and the practical skills and knowledge required to manage complex real-world projects [1]. As a result, the value of PM education and training has been questioned, as there is little empirical evidence indicating that trained or certified project managers are more successful than "accidental" project managers at dealing with complex problems [2].

In recent years, an increasing number of studies have attempted to address this concern by implementing "serious" or educational PM games as they have "the advantage of enabling participants to be put into complex, realistic project situations" [3]. These games could provide learners (players) with practical PM experience without exposing them to the risks or costs of managing real-world projects [4]. Consequently, serious games (SGs) offer significant value to educators and trainers who otherwise find it challenging to prepare learners to cope with project complexity [5].

One defect of SGs in general and project management serious games (PMSGs) in particular is oversimplification [6]. Oversimplification of PMSGs could hamper their ability to provide a realistic PM experience. Most PMSGs are developed, implemented and evaluated in an academic (university) setting without the involvement of experienced PM practitioners [7]. This is of concern as, unlike games designed for entertainment, SGs 
require close collaboration between domain experts (e.g., PM practitioners) and game designers [8] during their development in order to ensure realism and design quality. Furthermore, the literature on SGs provides little guidance on the principles of designing and implementing successful games [8]. This is also true in PMSG studies, which as yet include no research focused on providing comprehensive guidelines to assist PM educators and game designers in designing and implementing successful PMSGs.

In order to address the abovementioned concerns and gaps, this study melds three different perspectives (i.e., that of PM practitioners, SG designers, and students). This research aims to identify preliminary design and implementation principles of a successful PMSG through an identification of lessons learned from implementing such a game. The structure of this study is as follows. First, a definition of serious games is offered, followed by a discussion of their design and implementation principles. Thereafter, the gaps outlined in this section are elaborated by discussing several PMSGs proposed in the literature. Subsequently, this paper discusses the methodology adopted in this study, and present and discuss the results. The study concludes with a summary of the identified principles and a discussion of the potential implications and limitations of the research.

\section{Literature Review}

\subsection{Serious games: Definition}

Serious or educational games integrate the characteristics of "entertainment-focused" games and "education-focused" simulations. SGs are designed not only to engage learners [9] but also to facilitate learning and/or behavioral change [10]. Through playing these games, training participants or students can learn new skills and concepts and develop their existing knowledge [11]. These games are simplifications and condensations of real-world problems, which allow learners to safely experiment with (future) decisions and reflect on the outcome. In a number of iterations, learners make decisions, form coalitions, and/or negotiate on the basis of given and/or self-selected objectives or interests [12].

\subsection{Serious games: Design and Implementation Principles}

From the literature, this study identifies several principles of designing and implementing SGs. The first principle is that SGs must have clear educational goals [13]. Furthermore, there must be a balance between simplicity and realism. In the context of a simulation (and a SG), realism is defined as the extent to which the behavior and/or appearance of the game matches the behavior and appearance of the real system [14]. Realism is needed in PMSGs because it enables learners to develop and show complex project management skills which could not be lectured [3]. These skills are developed through experience in solving complex and realistic project situations. A SG should be as realistic as possible without compromising its educational value $[15,16]$. If an SG is too complex (or too realistic), players can be mired in detail rather than focusing on its key educational aspects. On the other hand, an overly simplistic SG may forfeit the ability to help learners deal with complex real-world problems.

High-quality games motivate learners to study and offer enjoyable learning experiences [13]. Motivation can be enhanced by providing players with challenge, curiosity, and autonomy [17]. In order to facilitate learning, the challenge should be just outside the players' current level of ability and should be progressive so that players can compete with themselves [18]. Elements of surprise in games help stimulate players' curiosity [17]. Furthermore, autonomy is established when players perceive themselves as the initiators of their decisions or actions [17]. 


\subsection{Examples of Existing Project Management Serious Games}

The literature, particularly that from the last two decades, contains numerous PMSGs. Interestingly, most of these games, such as PROSIGA [19] and SimProject [20] involved only students and researchers (or educators) in the design, implementation and evaluation stages. Hussein's [21] project risk management game is one of the few PM games that involved experienced PM practitioners. His approach was to identify risks that frequently arise in real-world projects and the corresponding mitigation strategies by interviewing several senior project managers. These were translated into the game design, and the learning experience offered by the resultant game was then tested on students.

The $\mathrm{C}^{2}$ game [22] is another example of a PM game that involved PM practitioners in the design process. In developing the game, Geithner and Menzel [22] interviewed an HR manager and a project manager to identify the risks, challenges, and stakeholder management aspects of a relocation project that was simulated in the game. The effectiveness of this game was then evaluated by university students. This study attempts to adopt the same integrative practitioner-student approach as utilized by Geithner and Menzel [22] and Hussein [21]. However, instead of focusing on learning experience or effectiveness, this study focuses on identifying the principles of successful PMSG design and implementation. Furthermore, this study also considered insights from SG experts to provide a more holistic framework. More examples of PMSGs are discussed in the subsequent sections.

\section{Methodology}

\subsection{Research Design}

In order to achieve the aim of this study, this study adopted a triangulation method [23, 24] in which two data collection techniques were applied within one study to minimize potential bias in the research findings. The methods applied in this study were both qualitative, as it did not intend to measure data tendencies [25]. Instead, the goal of this study was to explore PMSG design and implementation principles from different angles (i.e., that of students or users, experienced PM practitioners, and SG experts). The application of triangulation addresses a gap in current PMSGs research in which most games were evaluated only in a university context and did not involve these key entities [7]. Insights from PM practitioners are essential to ensure that the games simulate realistic PM problems. While perspectives from SG designers are needed to ensure that these problems are simulated appropriately in the games.

In the first stage of this explorative research, through applying a paper-based questionnaire (Figure 1), 283 Management of Projects master's degree students at a UK university who played the Project Crashing Games (PCGs) during a seminar session were asked to provide feedback on how the games could be improved. 


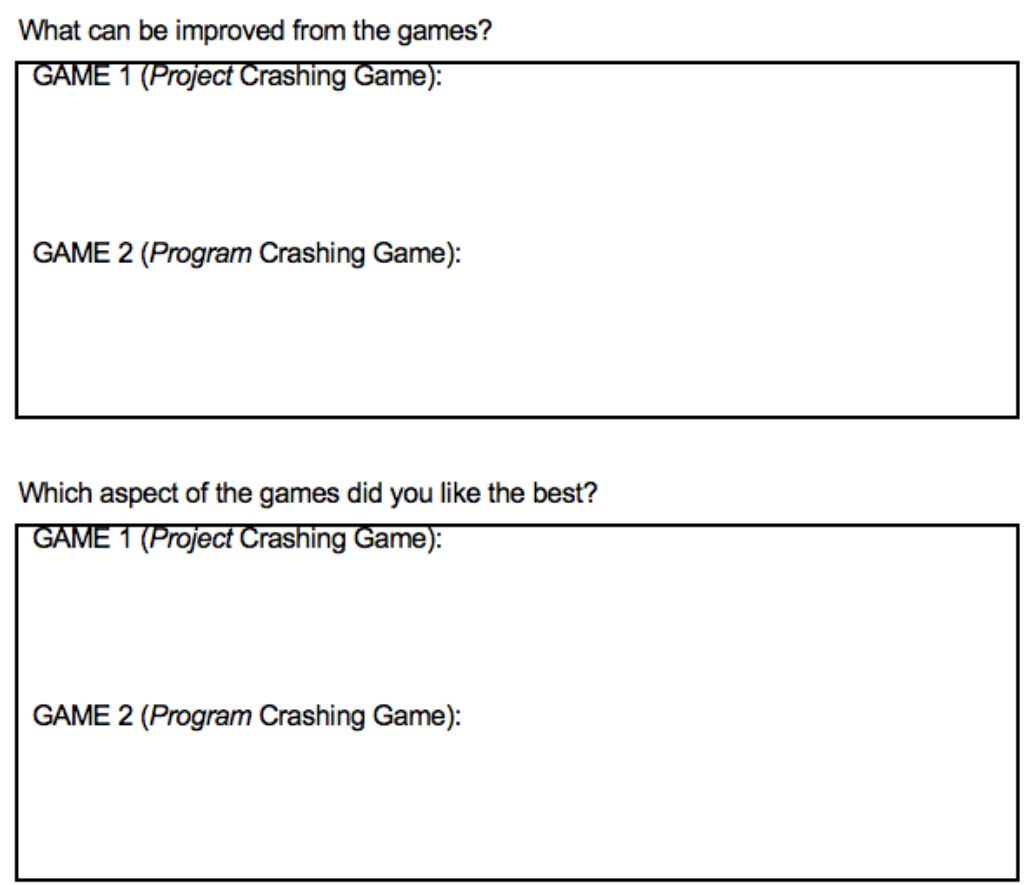

Figure 1. Paper-Based Questionnaire

This method was applied to provide preliminary identification of the lessons learned about the design and implementation of the games. The data collected were then analyzed using a content analysis method [26] in which responses with similar meanings or connotations were coded and aggregated into sub-themes or sub-categories, and similar sub-themes were coded and aggregated into themes. An example of this aggregation procedure is provided in the next section. In this stage, the content analysis method was applied to simplify numerous data for further analysis.

In the second stage of the study, the interviewer (main author) conducted a demonstration of the computer-based games (PCGs) and asked the same question (i.e. improvement suggestion feedback) of experienced PM practitioners and SG experts in oneon-one semi-structured interviews. Additionally, in each interview session, the author also asked the experts to comment on the students feedback (i.e., sub-themes) identified in the previous stage. In these interviews, experienced PM practitioners were asked to comment on project-related feedback, whereas students' gaming-related feedback was discussed with the SG experts. Eleven interviewees participated in this study:

- Five interviewees had more than five years of PM experience in total (i.e., as a project manager, program manager, program director, head of PM office, senior PM consultant, procurement coordinator, planning manager, or a combination of these roles). In the subsequent sections, these experts are referred to as "experienced PM practitioners".

- Two interviewees had more than five years of PM experience as well as extensive PMSG (or simulation) design experience, and another interviewee had more than four years' experience in both PM and SG design. In the following sections, these three experts are referred to as "PMSG experts".

- One interviewee had more than three years' experience in SG design, another interviewee designed multiple games for education and is a founder of a SG company, while a third had extensive experience in gamification, interaction design, user experience, and human-computer interaction. In the subsequent sections, these experts are referred to as "SG experts".

The purposes of the interviews were to compare the feedback from students to that from experts and to translate students' feedback into lessons learned or practical principles for designing and implementing successful PMSGs. A content analysis technique was also 
applied in this stage to simplify the numerous data into easier-to-comprehend information (i.e., design and implementation principles).

\subsection{Games Description}

The Project Crashing Games (PCGs) are ready-to-use online PM games that were developed by Rumeser and Emsley [27-30]. The PCGs' learning objectives are to teach project crashing (or acceleration) principles, the importance of critical path, and time-cost trade-offs at both project and program (or multi-project) levels.

The games were played in two stages. In the first stage, students played in small teams at a project level in which they selected activities to crash (accelerate) based on the activities' crash cost per day and crash availability. When a team crashed non-critical activities, an angry project sponsor avatar was displayed at each iteration. If a team managed to achieve the target project duration within a specified budget by crashing critical path activities (which were highlighted in the network diagram), a happy project sponsor avatar was displayed at the end of the game.

The duration of this game was 20 minutes and it was played in multiple iterations, as teams could only crash one day per activity in each iteration. Multiple attempts were allowed. The winner of the game was the project team who was first to achieve the cost and time objective. A dynamic leaderboard that ranked each team was displayed on large LCD screens, which were visible to all teams.

The second stage of the PCGs was played in a more complex multi-project context. For instance, Project Teams 1-5, who had previously played separately, were now required to collaborate in a larger program group (Program Group A); Project Teams 6-10 worked together in Program Group B, and so on. As in the first stage, teams crashed (accelerated) activities in their own project by taking account of activities' crash cost per day and crash availability. However, the goal was to achieve the overall program goals (i.e., cost and schedule).

In the program network diagram, each project was connected to other projects in a finish-to-start constraint (i.e., a project could be started once another project had been completed). Teams were allowed to use a chat box embedded in the game or to communicate verbally with other teams within the same program. Some teams assigned project and/or program managers to manage communication. The mechanism of this game was similar to that used in the first stage. Program groups had 30 minutes to achieve their goals, and the winner was the first group to achieve these. A dynamic leaderboard ranking each program group was displayed on large LCD screens, which were visible to all groups. As in the first stage, students were also asked to share the lessons they had learned from playing the game in the debriefing session.

In designing these games, Rumeser and Emsley [27] omitted any context from the project or activities (i.e., Activity or Project "A", "B", and "C" were used instead of "laying foundation" or "user acceptance test"). Furthermore, other PM aspects, such as resource allocation and limitation, vendor selection, resource sharing, risk and stakeholder management aspects, were not simulated.

The PCGs are developed on the basis of Kolb's experiential learning theory (ELT) [27, 31] which emphasizes knowledge acquisition through experience that consists of four successive cyclical stages. The first stage is concrete experience where players make decision in selecting activity to crash. Furthermore, players reflect on the effect of their decision on project performance (reflective observation) which helps them to conceptualize crashing principles (active experimentation). The final stage is active experimentation where players apply and test these principles or concepts in the subsequent iteration (active experimentation). Kolb's ELT receives criticisms because it does not adequately take account of the relationship between personal and social learning [32]. In PCGs, both 
pag. 76

personal and social learning are encouraged through simulating collective activities that require participants to share their knowledge [33].

\section{Project-Related Improvement Suggestions}

The project-related improvement feedback provided by the students is displayed in Table 1. These themes center on PM aspect of the games that can be improved. The themes displayed in the table were identified based on the open-ended question of game improvement feedback submitted by the students after playing the PCGs. NVivo (qualitative data analysis) software was used to analyze and code each student's response by adding "nodes" or "tags". Similar "nodes" (sub-themes) were aggregated into themes based on their similarities.

Table 1. Project-Related Improvement Ideas Proposed by Students

\begin{tabular}{|c|c|c|c|}
\hline \multicolumn{2}{|c|}{ Project-related theme } & \multicolumn{2}{|c|}{ Project-related sub-theme } \\
\hline Code & Description & Code & Description \\
\hline \multirow[t]{3}{*}{ SI-1 } & \multirow{3}{*}{$\begin{array}{l}\text { Project } \\
\text { complexity and } \\
\text { challenge }\end{array}$} & SI-11 & Allow students to adjust complexity level \\
\hline & & SI-12 & Adding project tasks \\
\hline & & SI-13 & Not highlighting critical path \\
\hline \multirow[t]{2}{*}{ SI-2 } & \multirow{2}{*}{$\begin{array}{l}\text { Additional and } \\
\text { alternative project } \\
\text { performance } \\
\text { indicator }\end{array}$} & SI-21 & More project objectives can be added \\
\hline & & SI-22 & $\begin{array}{l}\text { Instead of having a set goal on time and cost, let } \\
\text { the student find the optimum time and cost }\end{array}$ \\
\hline SI-3 & $\begin{array}{l}\text { Importance of } \\
\text { adding project } \\
\text { context }\end{array}$ & SI-31 & $\begin{array}{l}\text { Add project context (example) into the game to } \\
\text { improve understanding }\end{array}$ \\
\hline SI-4 & $\begin{array}{l}\text { Project and } \\
\text { program managers } \\
\text { assignment }\end{array}$ & SI-41 & $\begin{array}{l}\text { Facilitator should assign project managers and } \\
\text { a program manager before the game starts }\end{array}$ \\
\hline
\end{tabular}

Note: “SI' denotes Students' Improvement feedback

For example, a gaming-related sub-theme (or "node") coded SI-12, or "Adding project tasks" (Table 1), was constructed from similar students responses such as "More activities" and "Add more activities to make it harder." This node and other similar nodes (e.g., "Allow students to adjust complexity level", coded SI-11, and "Not outlining critical path", coded SI-13) were then aggregated into the "Project complexity and challenge" theme (SI-1).

The project-related improvement feedback offered by PM and SG experts is displayed in Table 2 . The themes and sub-themes in both tables were identified by analyzing and coding the semi-structured interview transcripts using the same coding and aggregation principles described in the Methodology section and exemplified at the beginning of this section.

Table 2. Project-Related Improvement Ideas Proposed by Experts

\begin{tabular}{l|l|l|l}
\hline Project-related theme & Project-related sub-theme \\
\hline Code & Description & Code & Description \\
\hline EI-1 & $\begin{array}{l}\text { Ethics, random } \\
\text { events, and } \\
\text { stakeholder } \\
\text { management }\end{array}$ & EI-11 & $\begin{array}{l}\text { Insert elements of ethics, random events, and } \\
\text { stakeholder management }\end{array}$ \\
\hline EI-2 & & EI-21 & $\begin{array}{l}\text { Simulate resource limitation and apply costs } \\
\text { when assigning resources }\end{array}$ \\
\hline
\end{tabular}




\begin{tabular}{|c|c|c|c|}
\hline & \multirow{2}{*}{$\begin{array}{l}\text { Resource } \\
\text { limitation and } \\
\text { selection }\end{array}$} & EI-22 & $\begin{array}{l}\text { Insert different resource and/or vendor profile } \\
\text { in resource selection }\end{array}$ \\
\hline & & EI-23 & $\begin{array}{l}\text { Simulate resource movement between } \\
\text { projects in the program }\end{array}$ \\
\hline \multirow[t]{3}{*}{ EI-3 } & \multirow{3}{*}{$\begin{array}{l}\text { Additional project } \\
\text { performance } \\
\text { indicator }\end{array}$} & EI-31 & $\begin{array}{l}\text { Add number of game attempts (i.e., trials) as } \\
\text { an additional project performance indicator }\end{array}$ \\
\hline & & EI-32 & $\begin{array}{l}\text { Insert project performance (i.e., not only } \\
\text { program performance) as an additional } \\
\text { performance indicator }\end{array}$ \\
\hline & & EI-33 & $\begin{array}{l}\text { Add customer satisfaction as an additional } \\
\text { performance indicator }\end{array}$ \\
\hline \multirow[t]{7}{*}{ EI-4 } & \multirow[t]{7}{*}{$\begin{array}{l}\text { Importance of } \\
\text { project context }\end{array}$} & EI-41 & $\begin{array}{l}\text { Add more project context into the game; the } \\
\text { context should be relevant to students' } \\
\text { background }\end{array}$ \\
\hline & & EI-42 & $\begin{array}{l}\text { Project problems or cases should be given in } \\
\text { different contexts. This enriches students' } \\
\text { learning experience }\end{array}$ \\
\hline & & EI-43 & $\begin{array}{l}\text { Context is needed to provide a sense of } \\
\text { realism that engages learners, so that it is not } \\
\text { only about mathematical calculation }\end{array}$ \\
\hline & & EI-44 & $\begin{array}{l}\text { Context is needed to improve learning } \\
\text { retention: people remember stories }\end{array}$ \\
\hline & & EI-45 & $\begin{array}{l}\text { Context is needed to help students } \\
\text { comprehend PM principles (e.g., task } \\
\text { dependencies, crashing availability) }\end{array}$ \\
\hline & & EI-46 & $\begin{array}{l}\text { PM games without context do not appeal to } \\
\text { any emotional drivers. In projects, emotional } \\
\text { drivers are important factors }\end{array}$ \\
\hline & & EI-47 & $\begin{array}{l}\text { Without context, PM games can promote } \\
\text { random trial and error (i.e., gambling } \\
\text { behavior) instead of attempts to understand } \\
\text { the problem }\end{array}$ \\
\hline \multirow[t]{2}{*}{ EI-5 } & \multirow{2}{*}{$\begin{array}{l}\text { Inter-project link } \\
\text { and complex } \\
\text { dependencies } \\
\text { within the } \\
\text { projects } \\
\end{array}$} & EI-51 & $\begin{array}{l}\text { Add inter-project links and the types of } \\
\text { dependencies between projects within the } \\
\text { same program }\end{array}$ \\
\hline & & EI-52 & $\begin{array}{l}\text { Not all projects in a program are dependent on } \\
\text { each other }\end{array}$ \\
\hline \multirow[t]{3}{*}{ EI-6 } & \multirow{3}{*}{$\begin{array}{l}\text { Realism of the } \\
\text { roles and } \\
\text { selection process } \\
\text { of project and } \\
\text { program } \\
\text { managers }\end{array}$} & EI-61 & $\begin{array}{l}\text { Program managers focus on benefit } \\
\text { realization }\end{array}$ \\
\hline & & EI-62 & $\begin{array}{l}\text { In the real world, project and program } \\
\text { managers would be selected by the project and } \\
\text { program sponsors, not by the team }\end{array}$ \\
\hline & & EI-63 & $\begin{array}{l}\text { In the gaming world, an ice-breaking session } \\
\text { can be implemented to select team leaders }\end{array}$ \\
\hline \multirow[t]{2}{*}{ EI-7 } & \multirow{2}{*}{$\begin{array}{l}\text { Number of } \\
\text { activities and } \\
\text { projects }\end{array}$} & EI-71 & Flexibility in adding task(s) or project(s) \\
\hline & & EI-72 & More activities to improve realism \\
\hline \multirow[t]{2}{*}{ EI-8 } & \multirow[t]{2}{*}{$\begin{array}{l}\text { Other project } \\
\text { complexity and } \\
\text { challenge factors }\end{array}$} & EI-81 & $\begin{array}{l}\text { Introduce penalty/reward clause (i.e., for } \\
\text { delivering the project later or faster than } \\
\text { expected) }\end{array}$ \\
\hline & & EI-82 & $\begin{array}{l}\text { Simulate a renegotiation scenario for activities } \\
\text { completed by external parties }\end{array}$ \\
\hline
\end{tabular}




\begin{tabular}{l|l|l}
\hline & EI-83 & $\begin{array}{l}\text { Add non-linearity in calculating project } \\
\text { attributes }\end{array}$ \\
\cline { 3 - 3 } & EI-84 & $\begin{array}{l}\text { Not clearly outlining the critical path to make } \\
\text { the game more challenging (depends on the } \\
\text { maturity level of the students) }\end{array}$ \\
\hline
\end{tabular}

Note: "EI” denotes Experts' Improvement feedback

In the following sub-sections, this paper translates students' improvement suggestions into PMSG design and implementation ideas by comparing and contrasting all students' feedback (Table 1) with all of the feedback from PM and SG experts (Table 2). Furthermore, this paper enriches the discussion by adding relevant insights and PMSG examples drawn from the literature.

\subsection{Increasing Project Complexity and Challenge}

\subsubsection{Adding Tasks and Projects}

Students suggested increasing the challenge and complexity level of the simulated project by adding the number of tasks (SI-12) and not outlining the critical path in each iteration (SI-13). The idea of adding activities was also encouraged by a PMSG expert, as this could improve the realism of the game (EI-72). Likewise, the suggestion to not highlight the critical path in each iteration in order to make the game more challenging was supported by another PMSG expert, who also stressed that this is advisable if the students have an adequate level of PM knowledge and skills (EI-84).

In addition, the PMSG expert suggested a feature that enables educators to flexibly adjust the number of projects and tasks (EI-71) so that the game can be targeted to students with different levels of knowledge and skills: "It would be marvelous if you could have flexibility in the number of projects and the number of tasks ... so you can play with [or] adjust the complexity or the simplicity depending on the type of students you've got." This suggestion aligns with Denholm and Stewart's proposal [34] that PM games should be "adaptable to simulate any size or scale of project over varying timespans."

\subsubsection{Inserting Elements of Ethics, Random Events, and Stakeholder Management Aspects}

During the interviews, experienced PM practitioners proposed other suggestions aimed at improving the realism of the game. One experienced PM practitioner highlighted that, in reality, non-technical factors exist that can affect PM decisions. He mentioned that ethical restrictions (e.g., the requirement not to violate maximum working hours) when crashing or accelerating projects is one such example, which could be inserted to increase verisimilitude (EI-11).

Furthermore, another PM practitioner noted that the game is missing the injection of random events. For instance, he suggested that sometimes "clients can be completely unreasonable about what needs to be done and by when." He stressed that the challenge is then to manage stakeholders' expectations. ARMI is an example of a project risk management game that simulates controlled randomness [35]. In the game, students learn that consultants' or experts' opinions on risks are not always correct.

\subsubsection{Simulating Resource Limitation, Selection, Penalty/Reward, and Renegotiation Scenarios}

Another aspect of project complexity not simulated in the PCGs is resource selection and allocation decisions that consider resource limitations and costs (EI-21) as well as resource or vendor profiles (EI-22). Commenting on the games, one of the PMSG experts stated: "There's no resourcing, there's no resource limitations in this model at the moment. So, if I was able to crash task $\mathrm{A}$ on the cost of $£ 20$ a day, ... I would expect that to increase the 
demand for a specific resource and that might put me up to some kind of resource availability limit." Although the games simulate limited crashing availability of each task, the expert's assertion on resource limitation is correct as there is no explicit reference on this in the games (e.g., staff A can only work 20 hours in a particular week).

Another PMSG expert added: "[Y]ou can offer them sort of which contractors would you [select] on the basis of the information you have been given by them. And you judge for the [reliability], judge the cost and time, the lead time, whether you think it stacks up and will actually happen .... " A construction procurement negotiation game [36] is an example of a PM game that simulates essential factors influencing procurement decisions, such as uncertainty in supplier work quality and the delivery schedule.

Another aspect complicating vendor selection is a penalty/reward mechanism for delivering the project later or earlier than expected (EI-81). In the PMT game [37], for instance, players are incentivized to complete the project as early as possible to maximize profit. In the case of late completion, a penalty is paid. If they manage to complete the project earlier than expected, the profit increases as a daily bonus is added thereto. Furthermore, one of the PMSG experts also suggested simulating a renegotiation scenario for activities completed by external parties (EI-82). This affects the cost of accelerating a task, which - in reality - is often not linear. Contractors may charge exponentially higher rates for each accelerated project day (EI-83).

\subsubsection{Simulating Resource Sharing Between Projects Within A Program}

To increase complexity and realism when playing the games at the program (i.e., multiple projects) level, one PMSG expert suggested that an important issue in program management that is not yet simulated in the PCGs is the scenario of resource movement or transfer from one project to another (EI-23). An experienced PM practitioner added, "maybe there are conflict of resources, so you might have a really skilled resource, but you can only apply them in one place, not both [projects], so then that's the discussion about ... who gets the benefit of that skilled resource and why?" The PTB game [38], for instance, simulates this scenario by providing players with a program management case wherein resources are shared among several projects.

\subsubsection{Increasing Dependency Complexity Between Projects Within a Program}

Other aspects that can be considered to increase the complexity of the simulated program are the types of dependencies between each project and the inter-project links (EI-51). In the PCGs, each project is connected via a finish-to-start dependency, meaning the first activity of a subsequent project can be started only once the final activity of the previous project (i.e., the predecessor) is complete. Other dependency types (e.g., start-to-finish, start-to-start, and finish-to-finish) could be simulated to improve the realism of the games.

Furthermore, in reality, the predecessor of the first activity in a project is not always the last activity in the previous project. According to two experienced PM practitioners, the assumption that a particular project can only be commenced after another project has been completed could be valid in a construction project, but may not apply to other project types. Another experienced PM practitioner suggested that, in his experience, not all projects in a program have task dependencies with each other (EI-52). Some projects are classified in the same program group not because of their task dependencies but because these projects are similar to each other or share a common benefit.

\subsection{Inserting Additional and Alternative Performance Indicators}

With regard to the objective of the simulated project, the students suggested inserting additional project objectives (SI-21) and an alternate objective of the game, namely to find 
the optimum balance between project time and cost (SI-22). These suggestions align with what the experts proposed in the interview.

The first suggestion was to add the number of game attempts (or trials) as an additional project performance indicator or objective (EI-31). According to one of the SG experts, the games need to represent real-world PM conditions, where making mistakes have consequences. Therefore, although unlimited attempts allow students to learn by trial and error, students must understand the consequences of making decision errors. Hartman et al. [39] took extreme measures in this regard by only allowing players a single attempt at playing a PM game. They argued that this "one and done" run encourages students to identify with the role of project manager and discourages them from "gaming the simulation."

In an interview session, an SG expert also suggested adding project performance (i.e., not only program performance) as a performance indicator (EI-32). This will make the game more challenging due to a mixture of competition between project teams within the same program and between different program teams. Furthermore, a PMSG expert suggested inserting customer or client satisfaction as an additional project and program performance indicator to improve realism (EI-33). One of the PMSG experts commented: "If you want to assess project performance in terms of time and cash, that's fine, but as an additional scoring technique ..., you could say: 'You've just had an email from the customer, really happy to hear that the project is going on time. Well done!" "At program (i.e., multiple projects) level, the degree of client satisfaction is an important aspect of benefit realization that could also be simulated in the game (EI-61).

With regard to students' suggestion to alter the game objective to establish the optimum balance between time and cost, instead of achieving a target schedule and cost (SI-22), a SG called PROSIMULA [40] provides the perfect example. In this game, players are provided with the flexibility to set their own project objectives (e.g., optimizing quality, time, or cost). This then determines their strategy when playing the game. Providing players with this type of autonomy is advisable, since it enhances their motivation during the learning process [17].

\subsection{Adding Project Context into the Games}

\subsubsection{Engaging Different Learners with Multiple Backgrounds}

Another recommendation for improvement offered by the students is to add project context into the game in order to improve understanding (SI-31). The experts further elaborated on this aspect during the interviews. Two PMSG experts suggested that adding context into the game will only be effective if that context is relevant to students' background (EI-41). One PMSG expert highlighted an important question that must be considered when deciding on the context: "how are you making this relevant to your pupils and learners?" To further illustrate his point, the PMSG expert also provided a case or scenario example, as follows: "You work for a leading-edge technology company called Orange, and they're about to launch their new phone, which is a direct competitor with the leading phone manufacturer that goes by the name of another fruit ... The project, then, is about developing this product, but because you've heard ... [that your competitor is] about to launch their product next week, ahead of their usual September launch, ... you need to apply project crashing techniques, so that you get your product to market quicker."

A simpler generic context, as that illustrated by the expert, has the advantage of providing equal opportunity to a class of mixed backgrounds [41] while also making the game more appealing, realistic and motivating for players [42].

\subsubsection{Enriching Learning Experience}

In one of the interview sessions, an SG expert suggested that players should be provided with different contexts, as this could enrich their learning experience (EI-42). For instance, players are asked to play different types of projects (e.g., IT/software and construction). 
Specific IT or construction risks can then be inserted into the game in order to provide players with the awareness that each project type carries different risks, hence applying a one-size-fits-all solution to different problems could result in failure. This aligns with [43] assertion that "what works in project A, or situation X, might not work for project B, or situation Z."

\subsubsection{Providing a Sense of Realism}

In other interviews, an experienced PM practitioner and SG expert suggested that, without context, the game could be viewed merely as a mathematical exercise that does not provide players with any sense of realism (EI-43). The SG expert argued: "Because [the PCGs] have very plain design with project A, project B, the variable and everything, what I don't really see is the connection to real life problem." To provide players with a sense of realism, some PM games, such as ManuBuild [44] and PSG [45], were based on real-world projects.

\subsubsection{Improving Learning Retention}

One PMSG expert suggested that learners retain lessons longer when playing games with context compared to those without context, as people tend to remember stories (EI-44). Narrative passages (e.g., stories) are more readily remembered than expository and descriptive formats [46].

\subsubsection{Helping Students Comprehend Project Management Principles}

The addition of a project context into PM games is an important feature to help learners comprehend PM principles (EI-45). For instance, one experienced PM practitioner suggested that, by adding PM contexts, learners could more readily grasp the concept of limited crashing availability. The fact that some activities can be crashed only to a certain extent is self-explanatory when a context is provided (e.g., a project task of procuring a specific material can only be accelerated to a specific minimum duration, as suppliers need a minimum lead time for delivery). Similarly, learners can understand tasks dependencies more easily when provided with context. Instead of explaining dependencies by stating that Task B can only be started after Task A's completion, the addition of an additional narrative explaining, for instance, that the user acceptance test (Task B) can only be started after the initial software design (Task A) has been completed would improve understanding.

\subsubsection{Appealing to Emotional Drivers}

One of the PMSG experts argued that the games' lack of context is the reason why they fail to appeal to any of his emotional drivers (EI-46). Elaborating on this, an experienced project consultant highlighted the emotional aspects of PM, which are not sufficiently simulated in the games. This is an important aspect, as "projects are emotional" [47]; many decisions in projects are affected by emotions.

\subsubsection{Discouraging "Gambling” Behavior}

Furthermore, a SG expert also advised that a game lacking context could promote random trial and error (or "gambling") behavior rather than attempts to understand the problem (EI47). Instead of learning PM concepts by committing decision errors, students might be tempted to merely learn how to "play the game" [48] and identify patterns to win the game. This detrimental behavior can be discouraged by the addition of a PM context into the game.

\subsection{Assigning Project and Program Managers}

The last project-related suggestion from the students is that game facilitators should select and assign project and program managers (SI-41). This suggestion aligns with what happens in the real world, as project and program managers are usually assigned by project 
pag. 82

sponsors and not by the project or program team (EI-62). In the gaming world, on the other hand, an icebreaking session to facilitate the selection and assignment of team leaders is a common strategy utilized to help team members build trust, thereby putting them in a better position to identify and select potential leaders (EI-63). If the goal is to provide learners with a better sense of realism, the first option is preferable. Otherwise, the latter option (i.e., the icebreaking session) should be applied, given its potential to provide learners with a more engaging learning experience wherein they take control of their own decisions [17].

\section{Gaming-related improvement suggestions}

Applying the same content analysis procedure as utilized in the previous section, this paper identified fourteen students' gaming-related improvement suggestion sub-themes and six themes as set out in Table 3 .

Table 3. Gaming-Related Improvement Ideas Proposed by Students

\begin{tabular}{|c|c|c|c|}
\hline \multicolumn{2}{|c|}{ Gaming-related theme } & \multicolumn{2}{|c|}{ Game-related sub-theme } \\
\hline Code & Description & Code & Description \\
\hline \multirow[t]{2}{*}{ SI-5 } & \multirow[t]{2}{*}{$\begin{array}{l}\text { Game display } \\
\text { improvement }\end{array}$} & SI-51 & $\begin{array}{l}\text { Improve design attractiveness. Add more } \\
\text { illustrations and images to the game }\end{array}$ \\
\hline & & SI-52 & Elucidate project attributes display \\
\hline \multirow[t]{2}{*}{ SI-6 } & \multirow{2}{*}{$\begin{array}{l}\text { Clarity of gameplay } \\
\text { and interface }\end{array}$} & SI-61 & Improve gameplay instruction clarity \\
\hline & & SI-62 & $\begin{array}{l}\text { Clearly inform students how the interface } \\
\text { works }\end{array}$ \\
\hline SI-7 & $\begin{array}{l}\text { Theoretical input } \\
\text { before playing the } \\
\text { game }\end{array}$ & SI-71 & $\begin{array}{l}\text { Provide students with more theoretical inputs } \\
\text { before playing the games }\end{array}$ \\
\hline \multirow[t]{6}{*}{ SI-8 } & \multirow{6}{*}{$\begin{array}{l}\text { Game setting: } \\
\text { during play }\end{array}$} & SI-81 & Fewer groups when playing at program level \\
\hline & & SI-82 & $\begin{array}{l}\text { Roundtable seating layout should be applied } \\
\text { when playing the game at a program level; } \\
\text { project teams should sit closer to each other }\end{array}$ \\
\hline & & SI- 83 & Add more exercises (i.e., different scenarios) \\
\hline & & SI-84 & Change the format to single player \\
\hline & & SI- 85 & Extend the duration of the game \\
\hline & & SI-86 & Shorten the duration of the game \\
\hline SI-9 & $\begin{array}{l}\text { Game setting: } \\
\text { before play }\end{array}$ & SI-91 & $\begin{array}{l}\text { Allow students to practice before playing the } \\
\text { game }\end{array}$ \\
\hline \multirow[t]{2}{*}{ SI-10 } & \multirow{2}{*}{$\begin{array}{l}\text { Game setting: after } \\
\text { play }\end{array}$} & SI-101 & More time to retry the game after gameplay \\
\hline & & SI-102 & $\begin{array}{l}\text { Extend the duration for reflection after } \\
\text { gameplay }\end{array}$ \\
\hline
\end{tabular}

Note: 'SI' denotes Students' Improvement feedback

The gaming-related improvement feedback proposed by the PM and SG experts is displayed in Table 4 . Fifteen sub-themes and eight themes were identified by implementing the content analysis procedures outlined in the Methodology section. 
Table 4. Gaming-Related Improvement Suggestions Proposed by Experts

\begin{tabular}{|c|c|c|c|}
\hline \multicolumn{2}{|c|}{ Gaming-related theme } & \multicolumn{2}{|c|}{ Gaming-related sub-theme } \\
\hline Code & Description & Code & Description \\
\hline EI-9 & $\begin{array}{l}\text { Identify the players } \\
\text { (target groups) }\end{array}$ & EI-91 & $\begin{array}{l}\text { Define target groups' prior knowledge and } \\
\text { motivations }\end{array}$ \\
\hline EI-10 & Clear instruction & EI-101 & $\begin{array}{l}\text { Important to explain the instructions clearly } \\
\text { before playing the game }\end{array}$ \\
\hline EI-11 & Personalization & EI-111 & $\begin{array}{l}\text { Personalization (e.g., team name, avatar) is } \\
\text { needed to help players identify themselves as } \\
\text { teams, and to make the competition more } \\
\text { relevant to the players }\end{array}$ \\
\hline \multirow[t]{5}{*}{ EI-12 } & $\begin{array}{l}\text { Game design } \\
\text { improvement }\end{array}$ & EI-121 & $\begin{array}{l}\text { Alternative PM view: Gantt Chart and } \\
\text { resource histogram }\end{array}$ \\
\hline & & EI-122 & Graphical view may improve design \\
\hline & & EI-123 & Design should follow context \\
\hline & & EI-124 & $\begin{array}{l}\text { Efficient design: choose activity (or activities) } \\
\text { to crash directly on the network diagram }\end{array}$ \\
\hline & & EI-125 & $\begin{array}{l}\text { Project performance should be at the top (and } \\
\text { be at an adequate distance from other } \\
\text { graphs/numbers) }\end{array}$ \\
\hline \multirow[t]{2}{*}{ EI-13 } & $\begin{array}{l}\text { Improving } \\
\text { feedback clarity }\end{array}$ & EI-131 & $\begin{array}{l}\text { Highlight changes (e.g., changes in project } \\
\text { attributes and network diagram) }\end{array}$ \\
\hline & & EI-132 & $\begin{array}{l}\text { Adding positive feedback during the game } \\
\text { helps motivate players }\end{array}$ \\
\hline EI-14 & $\begin{array}{l}\text { Both verbal and } \\
\text { written } \\
\text { communication } \\
\text { modes are needed }\end{array}$ & EI-141 & $\begin{array}{l}\text { Both verbal and written communication } \\
\text { should be used Chat box can be used as a PM } \\
\text { decision log. Lessons learned log }\end{array}$ \\
\hline \multirow[t]{2}{*}{ EI-15 } & Seating layout & EI-151 & Readjust seating layout (i.e., not in silos) \\
\hline & suggestion & EI-152 & $\begin{array}{l}\text { Seating layout constraint forms part of } \\
\text { communication challenge }\end{array}$ \\
\hline \multirow[t]{2}{*}{ EI-16 } & $\begin{array}{l}\text { Debriefing idea } \\
\text { (knowledge sharing }\end{array}$ & EI-161 & $\begin{array}{l}\text { Debriefing idea: sharing PM strategy } \\
\text { (strengths and weaknesses) }\end{array}$ \\
\hline & $\begin{array}{l}\text { and project support } \\
\text { office) }\end{array}$ & EI-162 & $\begin{array}{l}\text { Debriefing idea: Introducing project support } \\
\text { office to help analyze what went well and } \\
\text { what went wrong }\end{array}$ \\
\hline
\end{tabular}

Note: “EI' denotes Experts' Improvement feedback

\subsection{Improving Game Display}

Students suggested that the game display could be improved by adding additional images (SI-51) and elucidating the project attributes display (SI-52). In respect of these suggestions, one PMSG expert advised adding alternative PM views in the games, such as the Gantt chart and resource histogram views (EI-121). The latter view aligns with an earlier discussion on the insertion of resource limitation (EI-21) and resource sharing (EI-23) scenarios. The PMT is one example of a game that provides the resource histogram view [37], whereby the graph displays information on the maximum availability of each resource. The first view (i.e., Gantt chart) is useful for "hiding" the critical path, as suggested by both the students (SI-13) and the experts (EI-84). The PMG-2D game [49] displays this view, with the chart showing the progress of each project activity.

Despite suggesting multiple alternative PM views, one PMSG expert also stressed that this should not overcomplicate the design: the design must remain as efficient as possible. 
For instance, players can choose the activity they wish to crash (accelerate) by clicking that activity directly on the Gantt chart. Efficiency is critical to the quality of game design, as players should focus their cognitive efforts on the learning aspect of the game, not on the complexity of the gameplay and/or design objects [50].

Furthermore, in agreement with the students, one of the SG experts suggested applying more graphical views to improve the attractiveness of the display and clarity of the project attributes (EI-122). This could be manifested in the representation of activities (i.e., the addition of images that best reflect each activity). In other words, design should follow the project context (EI-123). For instance, administrative work can be represented by a letter icon, and construction work can be represented by an excavator icon.

Another way to improve the display is by adding images or illustrations to clarify each project attribute (e.g., by denoting activities that are expensive to crash by multiple dollar or pound sterling symbols). In the Project Challenge game [51], for example, a ship icon is displayed as a real-time project status indicator. If all project outcome measures are on target, the display shows "smooth sailing" in sunny weather. The weather becomes stormier the more the project performance deviates from the target. Furthermore, one PMSG expert also suggested positioning the final project performance (e.g., duration and cost) information at the top of the layout at an adequate distance from other objects and numbers so that players can clearly identify these key indicators (EI-125).

\subsection{Improving Gameplay Instruction and Interface Clarity}

A key lesson learned is not to assume that players can quickly grasp how the gameplay (SI61) and interface (SI-62) operate. When playing the game, students needed more time to understand its mechanics. Based on the main author's observations, students tended to disregard the instructions page, as they had limited time to solve the problem and were competing against other teams to be the first to achieve the game objectives. Rumeser and Emsley [27] might have been affected by designer bias whereby the repetitive tasks involved in designing, testing and solving the problems presented in the PCGs led them to falsely believe that students would quickly grasp the gameplay and interface.

With regard to this bias, one PMSG expert commented: "Some learners will look at this (timed interaction) and say: 'You want me to do this in [twenty] minutes? You might be able to do this in [twenty] minutes, because you're a PhD student.' Someone with less experience, they might need more time." The key lesson learned here is to split a session into two parts, with one game played for the purpose of understanding the gameplay and how the interface works, and the other played in a competitive and timed interaction setting (SI-91). In the first session, clear instructions should be provided (EI-101) until no students have any remaining questions in relation to the gameplay and interface, at which point the latter session can commence. To further enhance clarity, an un-skippable instruction video that walks the players through the interface can be shown before the game starts [52].

\subsection{Identifying Prior Knowledge and Motivations of the Learners}

Students' feedback suggests that some of them need more theoretical input before playing the game (SI-71). In this regard, one of the SG experts recommends defining the target audience of the game (EI-91), as this provides insights into the quantity of theoretical input required before the game is played. Learners' prior knowledge should be considered when applying any instructional (training) methods, not just SGs [53]. In PCGs, learners' prior knowledge changes as they complete the game in two stages (i.e. the less complex and the more complex stages). Rumeser and Emsley [27] suggest that playing the less complex stage (i.e. the first stage) is required in order to prepare learners to cope with the problems in the more complex stage (i.e. the second stage of the game). This aligns with Kolb's experiential learning cycle [54] that proposes the application of learning stages with increasing complexity level in order to enhance knowledge. 
Another reason for defining the target audience before implementing the games is that educators could identify the drivers that motivate players in order to make the game more engaging for them. An SG expert commented: "Usually in our games we try to integrate various levels of motivation because we know that some people are competitive ... Some people like to learn and develop themselves ... some people like seeing some feedback so ... that's why I think it is important to define your target group to understand their motivation and their purposes."

In addition to presenting the potential educational outcomes (i.e., by means of a "what you will learn from playing this game" slide), other researchers have introduced external drivers (rewards). For instance, Spowage et al. [41] awarded the game winner with a certificate of achievement from the Project Management Institute (PMI).

\subsection{Improving Feedback Clarity}

In relation to the feedback mechanism, this paper proposes two important lessons from interviewing one of the PMSG experts. First is the importance of highlighting changes in the project attributes to improve clarity (EI-131). For instance, if the project duration is reduced or delayed by one day (i.e., from 88 to 87 days or from 88 to 89 days), the addition of a delta sign showing the change in duration would improve clarity (Figure 2).

\section{Project Duration}

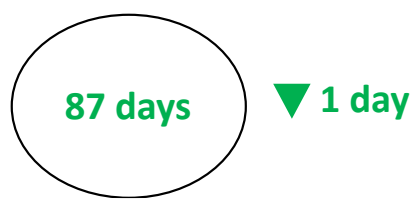

\section{Project Duration}

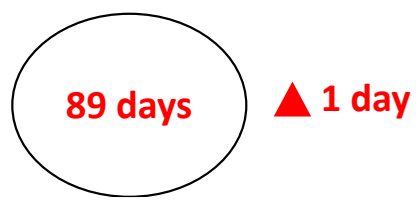

Figure 2. Highlighting Project Attribute Changes in the Design

The PMSG expert argued that highlighting such changes in project attributes gives: "learners immediate feedback that [they have] done something right or wrong." Furthermore, it is also important to provide players with instant positive feedback when they make correct decisions during the game and not only at the end of the game (EI-132). The PMSG expert commented: "In a real project, if one of my team does something well, I will tell you that they've done well. I won't wait until the end of the project. That's human interaction, to tell people that they've done something well, to get them to carry on doing things well. You've got to apply that same kind of philosophy when you're designing a game."

\subsection{Applying Flexible Game Settings and Deciding on Seating Layout}

Students provided diverse and sometimes contradictory feedback with regard to the game settings. Some suggested that the duration was too short (SI-85), while others suggested that it was too long (SI-86). Some players thought that the format should be changed to a single player design (SI-81), and others suggested reducing the number of groups when playing at the program level (SI-84). This further highlights the need to enable flexibility in the adjustment of settings during gameplay, as discussed earlier in Adding Tasks and Projects section. The idea of adding further exercises or different PM scenarios (SI-83) also aligns with the suggestion of an SG expert discussed in the Enriching Learning Experience section.

Furthermore, students suggested that a roundtable seating layout should be applied when playing the game at the program level (SI-82). By way of comment on this suggestion, 
pag. 86

one of the SG experts agreed that removing teams from silos would enhance the communication process. In contrast, another SG expert argued that seating layout constraints form part of a communication challenge that should be simulated. In light of these two contrary views, this study argues that the seating layout should be aligned with the learning objective. If that objective is to provide players with the experience of facing communication challenges in projects, the latter suggestion (sitting in silos) should be applied. Otherwise, the first suggestion (e.g., roundtable layout) should be implemented. The other key point is to prearrange the workstations as desired before the students enter the room in order to reduce setup time [55].

\subsection{Allowing Additional Time for Retrying the Game and Reflecting} on the Lessons

Some students requested additional time to retry the game (SI-101) and to reflect on the lessons (SI-102) after playing the game. These suggestions align with a learning theory put forward by [56] that highlights the importance of reflection-in-action (i.e., during the game) and reflection-on-action (i.e., after the game). The latter signifies the debriefing stage, which - together with the gameplay stage - provides players with opportunities to learn [57]. In this regard, one PMSG expert suggested two project-specific debriefing ideas. The first idea was to conduct a sharing session during which groups share their PM strategy and the strengths and weaknesses associated with this (EI-161). A systematic analysis of these strengths and weaknesses supports skills development [22].

Alternatively, a group can act as a project support office, whose role is to help analyze what went well and what went wrong in the work of other groups (EI-162). The PMSG expert explained the rationale behind the project support office idea, which he introduced in the debriefing session following one of his games: "If you ask each team to come to a session at the end and say about their own work, about their own history, they will be very dishonest. Oh, it all went rightfully well, it was all brilliantly good, and we had some bad luck, but it was a great success all around. So, by bringing a relatively outside view in [the project support office], it became a bit more realistic, it had been more honest." This notion aligns with a suggestion by [19] that someone ought to occupy the role of an observer, whose responsibility it is to watch and record participants' interactions as the game progresses.

\subsection{Other Gaming-Related Improvement Suggestions}

Several suggestions were raised not by the students but by the experts. First, both SG and PMSG experts advised enabling a personalization function, whereby players can choose their own team name and avatar (i.e., profile picture). This helps players to identify themselves as teams and makes the competition more relevant to the players. In the MAPLE game [17], for example, players can select and customize their own avatars. Ayk [17] argues that providing players with autonomy can improve their motivation to play the game.

Furthermore, one experienced PM practitioner highlighted the importance of using both verbal and written communication. While verbal communication is more practical, written communication (e.g., using chat boxes) can be used as a decision and/or lessons learned logs that are useful for recording key project decisions and lessons, respectively. Although each decision and its effects on project performance are automatically recorded in the PCGs system, players should nevertheless be encouraged to manually take notes of key project decisions and lessons. A study conducted by Davidovitch, Parush, \& Shtub [58] demonstrated that a manual history-recording mechanism could improve players' learning process. 


\section{Limitations}

The number of interviewees in this research is relatively small. However, the reliability of the findings was maintained as data saturation was seen to occur in the interviews and an additional triangulation method involving 283 students was applied. Furthermore, the methodology applied is aligned with the nature and purpose of this study, which was to explore preliminary PMSG design and implementation principles. Nevertheless, this paper suggests the application of a quantitative method in future research to test the framework suggested in this study. Quantitative approach (e.g. statistical analysis) can be applied to measure the relative importance of each design and implementation principle and to group these principles into categories in order to build a theoretical framework.

\section{Conclusions and implications}

The unique contribution of this research is that it is the first exploratory study to blend the perspectives of game users (students), serious game (SG) experts, and experienced project management (PM) practitioners in order to identify the key principles of delivering successful PMSGs. This study addresses the problems in existing PM games research, whereby most game design and evaluation involve only researchers and university students, which could result in a crucial gap between the skills acquired in the game and the skills required in practice. The identified principles (lessons learned) are summarized as follows.

\subsection{Game Realism}

This paper identified several ways to improve the realism of PM games, such as not highlighting the critical path in the network diagram and adding the number of tasks in a project or the number of projects in a program. Flexibility in adding tasks or projects is also recommended for the purposes of customizing the game in accordance with the prior knowledge of the target groups. Furthermore, elements of ethics (e.g., maximum working hours), random events (e.g., late materials delivery), stakeholder management (e.g., change requests), resource or vendor limitation, selection, penalty and reward clauses, and renegotiation scenarios can also be simulated to improve realism. At program (multipleprojects) level, complexity can be added by simulating resource conflict and resource sharing between projects. In addition, alternative performance indicators - such as customer satisfaction and number of game attempts - can also add realism. An alternative method is to provide players with the flexibility to choose their own project priorities and align their PM strategy accordingly.

\subsection{Game Context}

Experts recommended the application of a PM context relevant to learners' PM background and interests and the simulation of different PM scenarios or problems.

\subsection{Game Display}

This study suggests the use of illustrations and images rather than purely numerical project attributes. Alternative PM views such as Gantt charts and resource histograms can also be added. However, the design must remain efficient by minimizing redundancy. 


\subsection{Gameplay and Interface Clarity}

This study recommends the use of a separate session to facilitate learners' understanding of the interface and gameplay, with the main session being reserved for playing the game in competitive and timed interaction settings. Instruction videos may be used, provided these cannot be skipped.

\subsection{Target Audience}

This study suggests identifying the players (i.e., their PM background and motivations) prior to implementation.

\subsection{Feedback}

This study suggests providing instant feedback on the correctness or incorrectness of player decisions. This study also recommends highlighting changes (e.g., in project attributes or the network diagram) following each decision.

\subsection{Game Settings}

This study recommends the application of adjustable settings (i.e., duration, number of groups, multi- or single- player). In a program management setting, if realism is the goal, this study recommends that teams sit in silos to simulate communication challenges. If practicality is prioritized, this study recommends applying a roundtable seating layout to enhance communication.

\subsection{Debriefing}

Additional time can be provided to discuss the strengths and weaknesses of each team's PM strategy after playing the game, or an observer (e.g., a project support office) can be assigned to observe team interactions and identify which strategies succeeded and which failed.

The main potential beneficiaries of this research include PMSG designers, educators, trainers, students, and training participants. For designers, educators, and trainers, this study provides a comprehensive PM game design and implementation guideline that could help them avoid the mistakes often made when designing and delivering a PMSG. As SG design and implementation take time and effort, avoiding unnecessary errors and optimizing the value of their application is crucial. At the end of the day, improved PM game design and implementation will benefit the students and training participants.

Further research can be conducted based on the findings proposed in this study. The findings around practical recommendations to improving game realism provide a guideline for researchers to evaluate the positive and negative impact of realism and complexity in PMSGs. Researchers could also evaluate effectiveness of PMSGs on the basis of other variables proposed in this study, such as: game context, display, gameplay and interface clarity, target audience, feedback, game settings, and debriefing.

\section{Acknowledgment}

The authors gratefully acknowledge Lembaga Pengelola Dana Pendidikan (LPDP) as the main author's PhD sponsor. The authors would also thank Meidhy Praharsa Utama, Hari Wahyudi, and Budi Pratomo from PT. Pelabuhan Indonesia II (Persero), as well as Dr. Ian 
Stewart from The University of Manchester for comments that greatly improved the manuscript.

\section{References}

[1] J. Ramazani and G. Jergeas, "Project managers and the journey from good to great: The benefits of investment in project management training and education," International Journal of Project Management, vol. 33, no. 1, pp. 41-52, 2015. https://doi.org/10.1016/j.ijproman.2014.03.012

[2] L. Crawford, "Senior management perceptions of project management competence," International Journal of Project Management, vol. 23, no. 1, pp. 7-16, 2005. https://doi.org/10.1016/j.ijproman.2004.06.005

[3] S. Al-Jibouri, "The use of a simulation model as a game for teaching management of projects in construction," The International journal of engineering education., vol. 21, no. 6, p. 1195, 2005.

[4] A. R. Dantas, M. de Oliveira Barros, and C. M. L. Werner, "A simulation-based game for project management experiential learning," in Software Engineering and Knowledge Engineering (SEKE), Banff, Alberta, Canada, 2004, vol. 19, pp. 1-6: SEKE.

[5] J. Thomas and T. Mengel, "Preparing project managers to deal with complexity - Advanced project management education," International Journal of Project Management, vol. 26, no. 3, pp. 304-315, 2008. https://doi.org/10.1016/j.ijproman.2008.01.001

[6] B. A. Hussein, "On using simulation games as a research tool in project management," Organizing and learning through gaming and simulation, ISAGA, 2007.

[7] D. Rumeser and M. Emsley, "A systematic review of project management serious games: Identifying gaps, trends, and directions for future research," The Journal of Modern Project Management, vol. 6, no. 1, pp. 48-59, 2018.

[8] W. Seager, M. Ruskov, M. A. Sasse, and M. Oliveira, "Eliciting and modelling expertise for serious games in project management," Entertainment Computing, Article vol. 2, no. 2, pp. 7580, 2011. https://doi.org/10.1016/j.entcom.2011.01.002

[9] M. Hendrix, A. Al-Sherbaz, and B. Victoria, "Game based cyber security training: are serious games suitable for cyber security training?," International Journal of Serious Games, vol. 3, no. 1, pp. 53-61, 2016. https://doi.org/10.17083/ijsg.v3i1.107

[10] T. M. Connolly, E. A. Boyle, E. MacArthur, T. Hainey, and J. M. Boyle, "A systematic literature review of empirical evidence on computer games and serious games," Computers \& Education, vol. 59, no. 2, pp. 661-686, 2012. https://doi.org/10.1016/j.compedu.2012.03.004

[11] J. V. Dempsey, B. Lucassen, and K. Rasmussen, The instructional gaming literature: Implications and 99 sources. South Carolina: University of South Carolina, College of Education, 1996.

[12] I. Mayer and M. De Jong, "Combining GDSS and gaming for decision support," Group Decision and Negotiation, vol. 13, no. 3, pp. 223-241, 2004. https://doi.org/10.1023/B:GRUP.0000031076.98581.fc

[13] C. G. Von Wangenheim, R. Savi, and A. F. Borgatto, "DELIVER! - An educational game for teaching Earned Value Management in computing courses," Information and Software Technology, pp. 286-298, 2011.

[14] E. Farmer, J. Van Rooij, J. Riemersma, and P. Jorna, Handbook of simulator-based training. New York: Routledge, 2017. https://doi.org/10.4324/9781315253671

[15] I. Stewart, J. Denholm, and P. Blackwell, "Simulations in Project Management: Unexpected Events, Human Costs: Initiating an Autoethnographic Inquiry," in The 10th European Conference on Games Based Learning ECGBL 2016, Scotland, UK, 2016, pp. 644-650: Academic Conferences International Limited.

[16] S. Al-Jibouri and M. Mawdesley, "Design and experience with a computer game for teaching construction project planning and control," Engineering, Construction and Architectural Management, vol. 8, no. 5-6, pp. 418-427, 2001. https://doi.org/10.1046/j.1365232X.2001.00223.X

[17] A. Y. K. Chua and R. S. Balkunje, "An exploratory study of game-based m-learning for software project management," Journal of Universal Computer Science, vol. 18, no. 14, pp. 1933-1949, 2012. 
pag. 90

[18] Y. Inal and K. Cagiltay, "Flow experiences of children in an interactive social game environment," British Journal of Educational Technology, vol. 38, no. 3, pp. 455-464, 2007. https://doi.org/10.1111/j.1467-8535.2007.00709.x

[19] M. J. Saenz and J. L. Cano, "Experiential learning through simulation games: An empirical study," International Journal of Engineering Education, Article vol. 25, no. 2, pp. 296-307, 2009.

[20] K. Y. Jeong and I. Bozkurt, "Evaluating a Project Management Simulation Training Exercise," Simulation \& Gaming, Article vol. 45, no. 2, pp. 183-203, 2014. https://doi.org/10.1177/1046878113518481

[21] B. A. Hussein, "A blended learning approach to project risk management: Developing requirements and evaluating the student learning experience," Journal of Computing and Information Science in Engineering, Article vol. 11, no. 3, 2011, Art. no. 031004. https://doi.org/10.1115/1.3615971

[22] S. Geithner and D. Menzel, "Effectiveness of Learning Through Experience and Reflection in a Project Management Simulation," Simulation \& Gaming, Article vol. 47, no. 2, pp. 228-256, 2016. https://doi.org/10.1177/1046878115624312

[23] J. Grix, The foundations of research. London: Palgrave Macmillan, 2010. https://doi.org/10.1007/978-0-230-36490-5

[24] M. Saunders, P. Lewis, and A. Thornhill, Research Methods for Business Students, 4th edition ed. Harlow: Prentice-Hall, 2012.

[25] N. K. Malhotra and M. Peterson, Basic marketing research: a decision-making approach. New Jersey: Pearson, 2006. https://doi.org/10.1108/S1548-6435(2006)2

[26] R. P. Weber, Basic content analysis. Beverly Hills, CA: Sage Publications, 1990. https://doi.org/10.4135/9781412983488

[27] D. Rumeser and M. Emsley, "Design and Evaluation of the Project and Program Crashing Games," Journal of Applied Research in Higher Education, 2018.

[28] D. Rumeser and M. Emsley, "Can serious games improve project management decision making under complexity?," Project Management Journal, vol. 50, no. 1, pp. 23-29, 2018. https://doi.org/10.1177/8756972818808982

[29] D. Rumeser and M. Emsley, "Project Management Serious Games and Simulation: A comparison of three learning methods," The Journal of Modern Project Management, vol. 5, no. 3, pp. 62-72, 2018.

[30] D. Rumeser and M. Emsley, "Learning Style and Learning Method Preference in Project Management Education: What Happens When Things get More Complex?," in European Conference on Games Based Learning, Graz, 2017, pp. 860-865: Academic Conferences International Limited.

[31] D. A. Kolb, Experiential learning : experience as the source of learning and development. Englewood Cliffs, N.J.: Prentice-Hall, 1984.

[32] D. C. Kayes, "Experiential learning and its critics: Preserving the role of experience in management learning and education," Academy of Management Learning \& Education, vol. 1, no. 2, pp. 137-149, 2002. https://doi.org/10.5465/amle.2002.8509336

[33] C. Berggren and J. Söderlund, "Rethinking project management education: Social twists and knowledge co-production," International Journal of Project Management, vol. 26, no. 3, pp. 286-296, 2008/04/01/ 2008.

[34] J. A. Denholm and I. C. Stewart, "A Simulation for Planning and Executing a Project," in 10th European Conference on Games Based Learning Scotland, UK, 2016, pp. 159-167: Academic Conferences International Limited.

[35] S. Ramingwong and L. Ramingwong, "ARMI: A risk management incorporation," in 11th International Conference on Electrical Engineering/Electronics, Computer, Telecommunications and Information Technology (Ecti-Con), Nakhon Ratchasima, Thailand, 2014, pp. 1-6: IEEE. https://doi.org/10.1109/ECTICon.2014.6839802

[36] R. J. Dzeng, K. Y. Lin, and P. R. Wang, "Building a construction procurement negotiation training game model: Learning experiences and outcomes," British Journal of Educational Technology, Article vol. 45, no. 6, pp. 1115-1135, 2014. https://doi.org/10.1111/bjet.12189

[37] L. Davidovitch, A. Parush, and A. Shtub, "Simulation-based Learning in Engineering Education: Performance and Transfer in Learning Project Management," Journal of Engineering Education, vol. 95, no. 4, pp. 289-299, 2006. https://doi.org/10.1002/j.21689830.2006.tb00904.x 
[38] I. Cohen, M. Iluz, and A. Shtub, "A simulation-based approach in support of project management training for systems engineers," Systems Engineering, Article vol. 17, no. 1, pp. 26-36, 2014. https://doi.org/10.1002/sys.21248

[39] N. S. Hartman, C. A. Watts, and M. D. Treleven, "Appreciating the complexity of project management execution: Using simulation in the classroom," Decision Sciences Journal of Innovative Education, Article vol. 11, no. 4, pp. 323-334, 2013. https://doi.org/10.1111/dsji.12016

[40] S. Hofer, "Project management expertise through simulation," Cybernetics and Systems, vol. 27, no. 2, pp. 169-182, Mar-Apr 1996. https://doi.org/10.1080/019697296126624

[41] A. C. Spowage, C. M. M. Chin, K. Y. Chan, and K. N. Ting, "Educating engineers in the art, science and practice of project management: A new course," in 4th IEEE International Conference on Management of Innovation and Technology, ICMIT, Bangkok, Thailand, 2008, pp. 317-322: IEEE. https://doi.org/10.1109/ICMIT.2008.4654383

[42] Y. H. Perng, Y. K. Juan, and S. F. Chien, "Exploring the bidding situation for economically most advantageous tender projects using a bidding game," Journal of Construction Engineering and Management, Article vol. 132, no. 10, pp. 1037-1042, 2006. https://doi.org/10.1061/(ASCE)0733-9364(2006)132:10(1037)

[43] A. Jain and B. Boehm, "SimVBSE: Developing a game for value-based software engineering," in Software Engineering Education Conference, Proceedings, Turtle Bay, HI, 2006, vol. 2006, pp. 103-111: IEEE.

[44] J. Goulding, W. Nadim, P. Petridis, and M. Alshawi, "Construction industry offsite production: A virtual reality interactive training environment prototype," Advanced Engineering Informatics, Article vol. 26, no. 1, pp. 103-116, 2012. https://doi.org/10.1016/j.aei.2011.09.004

[45] M. Vanhoucke, A. Vereecke, and P. Gemmel, "The project scheduling game (PSG): simulating time/cost trade-offs in projects," Project Management Journal, vol. 36, no. 1, pp. 51-59, 2005. https://doi.org/10.1177/875697280503600106

[46] A. C. Graesser, N. L. Hoffman, and L. F. Clark, "Structural components of reading time," Journal of Verbal Learning and Verbal Behavior, vol. 19, no. 2, pp. 135-151, 1980. https://doi.org/10.1016/S0022-5371(80)90132-2

[47] N. Clarke, "Projects are emotional: how project managers' emotional awareness can influence decisions and behaviours in projects," International Journal of Managing Projects in Business, vol. 3, no. 4, pp. 604-624, 2009. https://doi.org/10.1108/17538371011076073

[48] M. Mawdesley, G. Long, S. Al-Jibouri, and D. Scott, "The enhancement of simulation based learning exercises through formalised reflection, focus groups and group presentation," Computers \& Education, Article vol. 56, no. 1, pp. 44-52, 2011. https://doi.org/10.1016/j.compedu.2010.05.005

[49] J. E. N. Lino, M. A. Paludo, F. V. Binder, S. Reinehr, and A. Malucelli, "Project management game 2D (PMG-2D): A serious game to assist software project managers training," in Frontiers in Education Conference (FIE), 2015. 32614 2015. IEEE, 2015, pp. 1-8. https://doi.org/10.1109/FIE.2015.7344168

[50] K. Kiili, "Digital game-based learning: Towards an experiential gaming model," The Internet and higher education, vol. 8, no. 1, pp. 13-24, 2005. https://doi.org/10.1016/j.iheduc.2004.12.001

[51] R. S. Taylor and M. T. H. Chi, "Simulation versus text: Acquisition of implicit and explicit information," Journal of Educational Computing Research, Article vol. 35, no. 3, pp. 289-313, 2006. https://doi.org/10.2190/403P-N4N2-6715-1515

[52] L. Poehler and T. Schumacher, "The virtual team challenge: Is it time for training?," in Portland International Conference on Management of Engineering and Technology, Portland, Oregon, 2007, pp. 2205-2211: IEEE. https://doi.org/10.1109/PICMET.2007.4349552

[53] P. A. Kirschner and J. J. G. van Merriënboer, "Do learners really know best? Urban legends in education," Educational psychologist, vol. 48, no. 3, pp. 169-183, 2013. https://doi.org/10.1080/00461520.2013.804395

[54] D. A. Kolb, Experiential learning: Experience as the source of learning and development. New Jersey: FT press, 2014.

[55] T. Hegazy, M. Abdel-Monem, D. A. Saad, and R. Rashedi, "Hands-On Exercise for Enhancing Students' Construction Management Skills," Journal of Construction Engineering and Management, vol. 139, no. 9, pp. 1135-1143, Sep 2013. https://doi.org/10.1061/(ASCE)CO.1943-7862.0000705 
pag. 92

[56] D. A. Schön, Educating the reflective practitioner: Toward a new design for teaching and learning in the professions. San Fransisco: Jossey-Bass, 1987.

[57] D. Crookall, "Serious games, debriefing, and simulation/gaming as a discipline," Simulation \& Gaming, vol. 41, no. 6, pp. 898-920, 2010. https://doi.org/10.1177/1046878110390784

[58] L. Davidovitch, A. Parush, and A. Shtub, "Simulation-based learning in engineering education: Performance and transfer in learning project management," Journal of Engineering Education, Article vol. 95, no. 4, pp. 289-300, 2006. 